\title{
Amputation Treatment with Least Number of Postoperative Complications based on the Atherosclerotic and Diabetic Changes of Blood Vessels of Lower Extremities
}

\author{
Demil Omerović ${ }^{1}$, Adnan Papović́ ${ }^{1}$, Adnana Talić-Tanović1, Edina \\ Tanović $^{2 *}$, Amila Jaganjac ${ }^{3}$, Hadžan Konjo ${ }^{3}$, Emina Rovčanin ${ }^{4}$ and \\ Hana Omerovićs \\ ${ }^{1}$ Ortopedics and Traumatology Clinic, Clinical Center University of Sarajevo, \\ Sarajevo, Bosnia and Hercegovina \\ ${ }^{2}$ Clinic for Physical Medicine and Rehabilitation, Clinical Center University of \\ Sarajevo, Sarajevo, Bosnia and Hercegovina \\ ${ }^{3}$ Faculty of Health Studies, University of Sarajevo, Sarajevo, Bosnia and Hercegovina \\ ${ }^{4}$ JZU Pharmacies of Sarajevo; Bosnia and Herzegovina \\ ${ }^{5}$ PZU Verdant Pharmacies; Sarajevo, Bosnia and Herzegovina \\ *Corresponding Author: Edina Tanović, Professor, Clinic for Physical Medicine \\ and Rehabilitation, Clinical Center University of Sarajevo, Sarajevo, Bosnia and \\ Hercegovina.
}

\author{
Received: October 03, 2020 \\ Published: October 22, 2020 \\ (C) All rights are reserved by Edina Tanović., et \\ al.
}

\begin{abstract}
Atherosclerosis is the most common arterial damage characterized by blood clotting due to the local thickening of the intima that is called atheroma or plaque. It is usually not diagnosed until critical stenosis, thrombosis, aneurysm or emboli occur. If severe artery clogging occurs, there is high risk for lower extremities, where gangrene appears to be the major consequence that has to be surgically treated by an amputation treatment. This study is a retrospective comparative study that includes 124 patients, both genders, of different age groups. The aim of the study is to show the effects of amputation procedures with the lowest complication rate due to lower extremity vascularization.

This study has shown that atherosclerotic and diabetic changes of the blood vessels of the lower extremities are more common in male gender, in the third age range where clogging is most often verified on the pedal arteries causing the gangrene of the toes. The most common surgical procedures are amputation of the toes with the most common complication defined as edge inflammation, while the lowest number of local complications was observed in the lower and upper leg amputations.

Since it has been proven that advanced atherosclerosis cannot fully regenerate, the goal of the treatment is to reduce the effect of the disease through prevention. Special attention should be made to male gender in third age range with comorbidities, and if the need for surgical treatment becomes necessary, it is to be realized in accordance with the findings of the blood flow rate at the lower extremities without delay.
\end{abstract}

Keywords: Atherosclerosis; Diabetes; Blood Flow Rate; Prevention; Amputation

\section{Introduction}

Atherosclerosis is the most common and most serious disease in a group of diseases called arteriosclerosis - a condition characterized by the fact that the artery wall becomes thinner and less elastic [1]. In atherosclerosis, this is caused by the formation of plaque or atheroma in the inner layers of the artery wall (intimae), which can reduce or obstruct blood flow. It is assumed that develops due to increased levels of fatty substances - LDL lipo- 
proteins in the blood and endothelial damage caused by different mechanism [2]. The most important risk factors for development of atherosclerosis are age, male sex and premature atherosclerosis in family history. Other risk factors are: elevated LDL levels and decreased HDL, hypertension, smoking, diabetes mellitus, obesity, and physical inactivity [3]. Of other risk factors, one of the most important in the sense of causing the most complex consequences is certainly diabetes mellitus [3-5]. Diabetes mellitus is a condition of chronic hyperglycemia, characterized by impaired carbohydrate metabolism, protein and fat. It can develop due to genetic predisposition, but external influences also have great influence [6]. It is caused by absolute or relative insulin deficiency, insulin resistance, increased glucose buildup, and enhanced hormone action whose effect is counteracted by insulin. Since chronic complications are responsible for the majority of morbidity and mortality associated with diabetes mellitus, there are three possible assumptions about the occurrence of chronic complications: increased glucose levels leads to increased production of final glucose products, that cause faster atherosclerosis and induces endothelial dysfunction; chronic hyperglycemia leads to increased sorbitol production leading to cellular dysfunction; hyperglycemia leads to enhanced formation of diacylglycerol that activates some forms of protein kinases involved in metabolic processes and causes diabetic complications [7-9].

Atherosclerosis is usually not diagnosed until critical stenosis, thrombosis, aneurysm or emboli occur. Symptoms of the disease usually develop gradually as the atheroma grows and closes the blood vessel lumen $[9,10]$. The first apparent inability to provide additional blood supply to individual organs at increased needs can be manifested by cardiac muscle tightness (angina pectoris), painful pulse in extremities (intermittent claudication). If a large artery occlusion happens, symptoms are much more dramatic, with a special focus on the lower extremities where gangrene can be the main consequence. Atherosclerosis is diagnosed on the basis of the above mentioned symptoms and signs and should be suspected if some risk factors are present [11]. Atheroma obstruction can be confirmed by arteriography (contrast blood vessel blood pressure scan) or doppler ultrasonography.

\section{Aim of the Study}

The aim of the study is to show the effects of amputation procedures with the lowest complication rate due to lower extremity vascularization.

\section{Materials and Methods}

Patients

This study is retrospective comparative study conducted at the Septic Department of the Clinic for Orthopedics and Traumatology of the University Clinical Center of Sarajevo in 2015 and 2016. Inclusion factors in the study are all patients hospitalized to perform operative amputation treatment, in which atherosclerosis of the lower extremities is diagnosed by doppler ultrasonography. The study included 124 patients, both genders, different age groups (usually the third age group). As complications of operative interventions we defined: inflammation, active secretion, necrosis and dehiscence, the need for a reoperative operation at the same level and above of the previous level of amputation.

\section{Statistical analysis}

Statistical analyses were performed with Statistical Package for Social Sciences (SPSS) 15.0 software (SPSS Institute, Chicago, IL, USA). Data were presented as number of cases and percentages. Testing of differences was performed using Chi-square test at 95\% confidence level $(\mathrm{p}<0.05)$.

\section{Results}

The study included 124 patients, both genders, of different age groups with ultrasound-verified atherosclerosis of the blood vessels of the lower extremities. All the patients involved in the study were divided by gender and age into four groups: 40 - 50 years of age, 50 - 60 years of age, 60 - 70 years of age and the fourth group were patients older than 70 years.

In relation to gender, 73 men and 51 women participated in the study. Statistical analysis by means of the hi-squares test indicates that there is no significant difference in sex distribution compared to the expected $\left(\chi^{2}=3,556 ; \mathrm{df}=1 ; \mathrm{p}=0,0593\right)$.

In relation to the age and gender, the most often atherosclerotic changes have been verified in the third group of the study. In the first age group (40 to 50 years) 7 male patients were registered, while there was no female patient with verified changes. In the second age group (50 - 60 years), 14 male had verified atherosclerotic changes and 16 female patients who participated in the study. With an increase in age, an increase in incidence of atherosclerotic changes has been observed in patients participating in the study, so in the third age group (60 to 70 years) 19 male and 14 female patients with changes were reported. The highest number of patients 
Amputation Treatment with Least Number of Postoperative Complications based on the Atherosclerotic and Diabetic Changes of Blood Vessels of Lower Extremities

was recorded in the fourth age group (older than 70 years), where 33 male and 21 female patients were registered with changes in the blood vessels. Statistical analysis by hi-squares test indicates that there is no significant difference in the age distribution of the sample in relation to gender $\left(\chi^{2}=6,871 ; \mathrm{df}=3 ; \mathrm{p}=0,0761\right)$.

Compared to the level of amputation, all procedures were divided into the following categories: toe amputation, partial foot amputation, below-knee amputation, above-knee amputation and disarticulation of the extremity. In 2016 at the Clinic for Orthopedics and Traumatology 45 toe amputations (36.3\% of surgical procedures), 19 partial foot amputations (15.3\%), 31 below-knee amputations (25\%), 27 above-knee amputations (21,7\%) and 2 disarticulations of the extremity (1.61\%) were performed. Statistical analysis using the hi-square test indicates that there is a significant difference in the distribution of the type of the operation in relation to the expected $\left(\chi^{2}=14,516 ; \mathrm{df}=4 ; \mathrm{p}<0,0001\right)$.

\begin{tabular}{|l|c|}
\hline Type of operative treatment & $\begin{array}{c}\text { Number and percentage of } \\
\text { operative treatment }\end{array}$ \\
\hline Toe amputation & $45(36,3 \%)$ \\
\hline Partial foot amputation & $19(15,3 \%)$ \\
\hline Below-knee amputation & $31(25 \%)$ \\
\hline Above-knee amputation & $27(21,7 \%)$ \\
\hline Desarticulation & $2(1,61 \%)$ \\
\hline
\end{tabular}

Table 1: Type, number and percentage of operative treatment performed.

In terms of gender and level of amputation, toe amputation was performed in 18 male and 27 female patients, partial foot amputation was performed in 10 males and 9 females, below-knee amputation in 17 males and 14 females, above-knee amputation in 13 males and 14 females, and two disarticulations of the lower extremity in male patients whereas none was observed in women. Statistical analysis by hi-squares test indicates that there is no significant difference in the level of amputation in relation to gender $\left(\chi^{2}=4,055 ; \mathrm{df}=4 ; \mathrm{p}=0,3986\right)$.

Local complications were recorded in 31 participants in the study (25\%), of which 22 in male and 9 in female patients. Statistical analysis by hi-squares test indicates that there is a significant difference in the representation of local complications in relation to gender $\left(\chi^{2}=4,645 ; d f=1 ; p=0,0311\right)$.

Inflammation was registered in 14 patients, active secretion in 6 patients, necrosis and dehiscence in 4 patients, the need for re- operation at the same level was performed in 4 patients, and reoperativne treatment above the previous level of amputation was performed in 3 patients. Statistical analysis using the hi-square test indicates that there is a significant difference in the types of local complications compared to the expected $\left(\chi^{2}=13,032 ; \mathrm{df}=4 ; \mathrm{p}=\right.$ 0,0111).

\begin{tabular}{|l|c|}
\hline Type of complication & Number and percentage \\
\hline Local inflammation & $14(45,16 \%)$ \\
\hline Active secretion & $6(19,35 \%)$ \\
\hline Necrosis & $4(12,9 \%)$ \\
\hline Reoperation & $4(12,9 \%)$ \\
\hline $\begin{array}{l}\text { Reoperation above the previous } \\
\text { level of amputation }\end{array}$ & $3(9,67 \%)$ \\
\hline
\end{tabular}

In relation to the level of performed amputation, the most complications were observed in toe (41\%) and partial foot amputation (31\%), while the lowest complications were recorded after the below-knee (9\%), above-knee amputation (11\%) and disarticulation (8\%). Statistical analysis using the hi-square test indicates that there is a significant difference in the representation of complications according to the types of surgery compared to the expected $\left(\chi^{2}=15,400 ; \mathrm{df}=4 ; \mathrm{p}<0,0001\right)$.

\section{Discussion}

Since it has been proven that advanced atherosclerosis cannot be completely regenerated, the goal of the treatment is to reduce the consequences of the disease through prevention. The prevention of atherosclerosis occurs in three stages: the prevention of the emergence of risk factors, prevention focused on existing risk factors before manifestation of signs of atherosclerotic changes and prevention after the onset of symptoms of atherosclerotic changes.

In a study conducted by Peng and Tan [12], the majority of respondents who were diagnosed with amputation were men, smokers, diabetics and the third age, as was demonstrated in our study where, in relation to gender, 73 men and 51 women participated in the study. In their research published in 1997, Ray and associates paid attention to clinical signs and predictors of amputation treatments, and recorded the highest percentage of gangrene of the toes, as was shown in our study, where 45 toe amputations were performed [13]. Zingg and associates have announced a study in which they investigated the indications and complications of lower limb amputations where they observed a large number of local complications, both for minor and major amputation treatments 
[14]. In our study, local complications were recorded in 31 patients (25\%) of which 22 in males and 9 in females. In relation to the level of performed amputation, the most complications were observed in toe (41\%) and partial foot amputation (31\%), while the lowest complications were recorded after the below-knee (9\%), aboveknee amputation (11\%) and disarticulation of the lower extremity $(8 \%)$.

\section{Conclusion}

Due to the extreme spread of the disease itself, treatment requires a multidisciplinary approach and cooperation at all levels of health care system. For the developed consequences of atherosclerotic changes in the blood vessels of the lower extremities, a timely reaction in terms of ultrasonography of blood vessels with determination of the proper level of amputation by angiologists and subsequent surgical treatment is of utmost importance. Special attention should be paid to male gender, third age of life and comorbidities, and if the need for surgical treatment occurs, it should be performed according to the blood flow of blood vessels without delay.

\section{Bibliography}

1. Beckman JA., et al. "Microvascular Disease, Peripheral Artery Disease, and Amputation". Circulation 140.6 (2019): 449-458.

2. Ramczykowski T and Schildhauer TA. "Amputation und Prothesenversorgung - die untere Extremität [Amputation of the Lower Limb - Treatment and Management]". Zeitschrift fur Orthopadie und Unfallchirurgie 155.4 (2017): 477-498.

3. Varma P., et al. "Epidemiology of limb loss". Physical Medicine and Rehabilitation Clinics of North America 25.1 (2014): 1-8.

4. Berli MC., et al. "Predictors for reoperation after lower limb amputation in patients with peripheral arterial disease". Vasa 48.5 (2019): 419-424.

5. Mustapha JA., et al. "Determinants of Long-Term Outcomes and Costs in the Management of Critical Limb Ischemia: A Population-Based Cohort Study". Journal of the American Heart Association 7.16 (2018): e009724.

6. Fard B., et al. "Mortality, Reamputation, and Preoperative Comorbidities in Patients Undergoing Dysvascular Lower Limb Amputation". Annals of Vascular Surgery 64 (2020): 228-238.

7. Hussain MA., et al. "Population-based secular trends in lowerextremity amputation for diabetes and peripheral artery disease". Canadian Medical Association Journal 191.35 (2019): E955-E961.
8. Reinecke H., et al. "Peripheral arterial disease and critical limb ischaemia: still poor outcomes and lack of guideline adherence". European Heart Journal 36 (2015): 932-938.

9. Kroger K., et al. "Lower Limb Amputation in Germany". Deutsches Ärzteblatt International 114 (2017): 130-136.

10. Swaminathan A., et al. "Lower extremity amputation in peripheral artery disease: improving patient outcomes". Vascular Health and Risk Management 10 (2014): 417-424.

11. Mills JL. "The application of the Society for Vascular Surgery Wound, Ischemia, and foot Infection (WIfI) classification to stratify amputation risk". Journal of Vascular Surgery 65.3 (2017): 591-593.

12. Malyar NM., et al. "Amputations and mortality in in-hospital treated patients with peripheral artery disease and diabetic foot syndrome". Journal of Diabetes and Its Complications 30 (2016): 1117-1122.

13. Narula N., et al. "Pathology of Peripheral Artery Disease in Patients with Critical Limb Ischemia". Journal of the American College of Cardiology 72.18 (2018): 2152-2163.

14. Spoden M., et al. "Amputation rates of the lower limb by amputation level - observational study using German national hospital discharge data from 2005 to 2015". BMC Health Services Research 19.1 (2019): 8.

\section{Assets from publication with us}

- Prompt Acknowledgement after receiving the article

- Thorough Double blinded peer review

- Rapid Publication

- Issue of Publication Certificate

- High visibility of your Published work

Website: www.actascientific.com/

Submit Article: www.actascientific.com/submission.php Email us: editor@actascientific.com

Contact us: +919182824667

Citation: Edina Tanović., et al. "Amputation Treatment with Least Number of Postoperative Complications based on the Atherosclerotic and Diabetic Changes of Blood Vessels of Lower Extremities". Acta Scientific Medical Sciences 4.11 (2020): 66-69. 